\title{
Del castillo medieval al palacio-fortaleza
}

\section{Concepción López González}

Universitat Politècnica de València, Instituto Universitario de Restauración del Patrimonio, Valencia, España

mlopezg@ega.upv.es

\begin{abstract}
During the Middle Ages in Valencia (Spain) innumerable castles, which eventually were abandoned and forgotten with the consequent ruin of their structures were built. Most of the construction material was reused in nearby homes. However, some of them continued inhabited, adapting to new social needs, which involved establishing spatial restructuring, extensions to locate new uses, specific reforms and opening new holes or divisions stays. To this must be added the reforms designed to increase comfort and beautification through factories based polychrome ornaments or decorative elements. The patios of weapons become arcaded courtyards and guard posts in private rooms. There are great examples of this type of transition fortified unfortunately have not stood the test of time, but which is still possible to appreciate its past splendor. This paper aims to identify patterns that are usually followed for the conversion of these castles palaces and establish an inventory of those fortifications whose conservation status still allows his speech, both aimed at the consolidation of structures to prevent total ruin as rehabilitation interventions in those who are in better shape. The data and results presented in this paper are the result of the research project entitled "Castles and fortresses in the province of Valencia" subsidized public call by the Universitat Politècnica de València
\end{abstract}

Keywords: palacio-fortaleza, castillo-palacio Valencia.

\section{Introducción}

La península ibérica, y más concretamente la zona situada en la franja mediterránea dispone de una red castral amplia y densa. Ello se debe a la estratégica posición que durante la edad media tuvo esta estrecha área territorial. En la época de dominio musulmán esta plana entre el mar y la meseta disponía de numerosos núcleos de población, alquerías en muchos casos, con su correspondiente torre vigía. En época cristiana, estas torres vigía fueron fortificadas y amuralladas convirtiéndolas en castillos cristianos, sobre todo en aquellas zonas fronterizas donde la defensa y control del territorio y de las vías de comunicación, tanto fluviales como terrestes, era fundamental para llevar a cabo la reconquista.
Muchos de estos castillos fueron abandonados con el paso del tiempo, cuando su función defensiva fue desapareciendo y sus estructuras y fábricas se fueron degradando paulatinamente hasta su ruina total.

Sin embargo, otros castillos fueron adaptándose a las nuevas necesidades sociales, modificando su organización espacial, sus estructuras e incluso sus elementos decorativos. Los austeros castillos medievales fueron reconvertidos en magníficos palacios o fortalezas actualizadas a las nuevas técnicas defensivas. Los muros compactos y faltos de vanos de las antiguas fortalezas, comienzan a abrirse al exterior. Los viejos techos de madera y las bóvedas de cañón construidas en piedra son sustituidas por 
bóvedas vaídas, aristadas sobre arcos formeros o con pequeñas cúpulas. Los patios de armas se convierten en claustros interiores a modo del cortile italiano y los pasos de ronda desaparecen en algunos casos.

La localización de la totalidad de estos palaciosfortaleza en la provincia de Valencia ha sido posible gracias a los resultados obtenidos en el proyecto de investigación subvencionado por la Universitat Politècncia de València en 2010 titulado "Catálogo razonado de castillos de la provincia de Valencia". Este proyecto tuvo una duración de tres años y en el mismo participaron profesores de diferentes áreas de conocimiento ${ }^{1}$.

La finalidad del mismo era la obtención de una base de datos de los castillos de la provincia de Valencia donde, además de los datos ya expuestos en otros inventarios realizados con anterioridad, figuraran datos novedosos y de gran interés para aquellos estudiosos de la castillología como son las coordenadas de localización $\mathrm{X}$ e $\mathrm{Y}$, la ruta de acceso, su inclusión en una ruta histórica de control del territorio, el estado de conservación de sus estructuras y el levantamiento de planos del conjunto arquitectónico, incluyendo un plano de situación sobre líneas de nivel donde se puede detectar la topografía del terreno con indicación del Norte y escala gráfica ${ }^{2}$.

Este análisis minucioso de cada uno de los castillos que se encuentran en la provincia de Valencia y alguno más situado en su confluencia con otras provincias aledañas, ha permitido detectar y catalogar aquellas fortalezas que se fueron adaptando a los nuevos tiempos, las nuevas necesidades sociales y los nuevos gustos estilísticos.

En esta comunicación se pretende exponer el inventario de palacios-fortaleza que no fueron abandonados en el periodo medieval $\mathrm{y}$ continuaron su existencia mediante intervenciones, modificaciones o ampliaciones de sus estructuras. La mayoría de ellos se encuentran en ruina progresiva y sólo algunos pocos como el de Bétera o Xátiva, de propiedad privada hasta hace poco, han sido conservados.

\section{La base de datos}

Para inventariar aquellos castillos medievales que fueron reconvertidos en fortalezas o palacios modernos se plantea un recorrido por cada una de las comarcas que componen la provincia de Valencia:

En el Rincón de Ademúz, sólo se encuentra un castillo que fuera adaptado a un uso que no fue el original. Se trata de una antigua fortaleza de origen musulmán conquistada por los cristianos en 1210. Una de las torres del recinto amurallado fue ampliada, tanto en altura como en superficie por los nuevos propietarios, la Orden de San Juan del Hospital, convirtiendo la nueva planta en templo y las plantas inferiores en asentamiento de la Encomienda.

Posteriormente esta gran mole de piedra fue adaptándose en sus usos a las diferentes necesidades sociales, de tal forma que en la actualidad aún es posible observar las marcas en los muros indicando hasta donde llegó el grano al ser convertida la planta inferior de la iglesia en almacén. La planta baja albergó una gran fragua que actualmente, aunque en desuso, conserva toda la maquinaria. Esta fortaleza no ha dejado de usarse desde su construcción, lo que ha contribuido a su buen estado de conservación ${ }^{3}$.

En la comarca de los Serranos se catalogaron doce castillos de los cuales sólo uno fue reconvertido en fortaleza moderna: El castillo de Chulilla. Tiene $230 \mathrm{~m}$. de largo y es un ejemplo de castillo adaptado a residencia palaciega aunque queda muy pocos vestigios de esta época. En el extremo sur, opuesto al acceso, se sitúa la plaza de armas y la torre del homenaje a la que se añadieron dependencias señoriales. También en el centro del recinto se encuentran dependencias abovedadas que probablemente no pertenecen al castillo original.

En la Vall d'Albaida ninguno fue transformado en época moderna.

De los ocho castillos que han sido catalogados en la comarca del Camp de Morvedre, cuatro fueron transformados en fortificaciones palaciegas: El castillo de Torres Torres fue 
adaptado como casa solariega nobiliaria, ampliando la torre del homenaje, tanto en anchura como en altura, modificando los huecos originales y abriendo otros en sus cuatro fachadas.
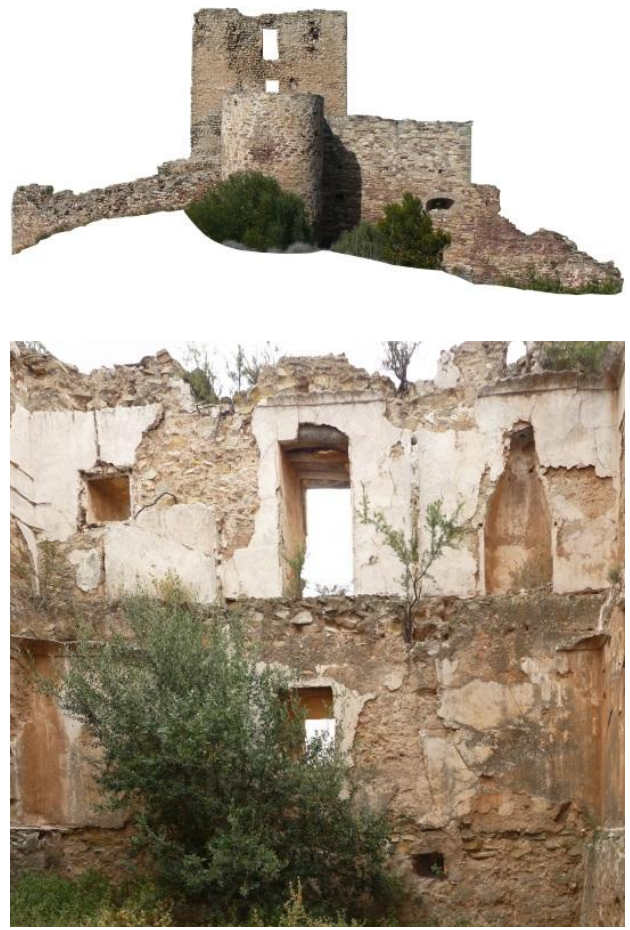

Fig. 1- Exterior e interior de la torre del castillo de Torres Torres situado en el valle del río Palancia

El castillo de Beselga, situado en el municipio de Estivella sobre una escarpada peña que domina el cauce del río Palancia al pie de la sierra Calderona y con un fértil valle a sus espaldas regado con las aguas de un manantial cercano, es otro de los castillos reconvertidos en vivienda palaciega. Su situación estratégica y las características de su entorno facilitaron el cambio de uso. Su origen se encuentra en una torre vigía musulmana que fue reconvertida en núcleo de comunicación vertical entre las diferentes plantas que componían el palacio que fue edificado en la celoquia del castillo. Se conservan los huecos con decorados de yesería tardogóticos y las improntas de las antiguas bóvedas que cubrían las diferentes dependencias. Siguiendo el cauce del río aguas abajo llegamos al castillo de Puinera situado sobre una leve sobreelevación del terreno a orillas del río, junto al núcleo de población. Está formado por un palacio gótico de planta cuadrada con patio interior y escalera de piedra en esquina alrededor del cual se encuentran las dependencias. Bajo el patio se ubica el aljibe abovedado. Este cuerpo está protegido por la antigua torre almenada de planta cuadrada.

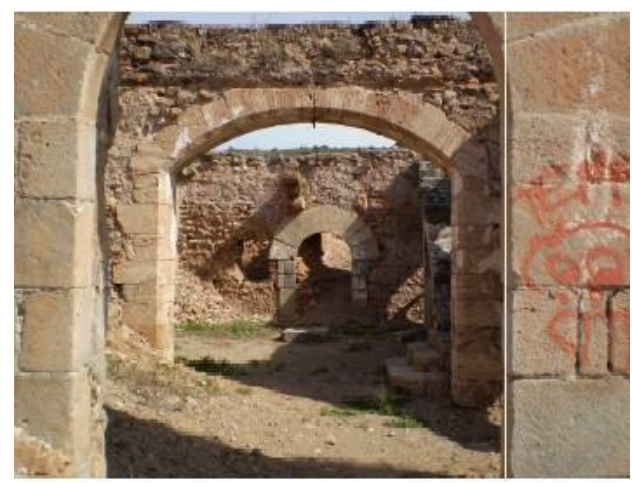

Fig. 2- Interior del Castillo de Puinera en Petrés con los restos de arcos adovelados pertenecientes al siglo XV

A pocos kilómetros río abajo, sobre un cerro estratégico que domina toda la plana costera, se sitúa el castillo de Sagunto. Han sido hallados en este lugar vestigios íberos, y a lo largo de los siglos ha sido reutilizado, ampliado $y$ modificado como fortaleza. Mayormente conocido por sus estructuras romanas, aunque la mayor parte de los restos que se conservan pertenecen a épocas posteriores con una superposición de técnicas y estilos que fueron yuxtaponiéndose hasta el siglo XIX.

En la Ribera Alta han sido catalogadas nueve fortalezas. De todas ellas sólo el Castillo de Alfarp ha seguido teniendo uso ininterrumpido desde su construcción. Ello se debe a la situación del mismo ya que se trata de una antigua torre vigía musulmana que daba protección a una importante alquería árabe que con el paso del tiempo se desarrolló como núcleo de población cristiano. La torre fue absorbida por una manzana en el centro de la actual población. En su base se encuentran varias lápidas de origen romano aunque los muros pertenecen a la época islámica. Ha sido rehabilitada recientemente. 
De los nueve castillos catalogados en la comarca de la Safor, tres fueron ampliados y reforzados en época moderna: El castillo de Marinyén en Benifairó de la Valldigna, de origen musulmán pasó a ser propiedad de la Orden del Cister. Mantiene restos de la torre del Homenaje y también del antiguo templo con bóveda de crucería. Se encuentra situado en un punto estratégico sobre un cerro en las faldas de la sierra, dominando el valle de la Valldigna. Las fábricas de mampostería y los muros de sillería en la capilla, así como los huecos abiertos al exterior demuestran las transformaciones sufridas en esta fortificación de origen árabe. El Castillo de Bairén, también denominado de San Juan se encuentra a 3 kilómetros al norte de Gandía en el extremo más oriental de la sierra de Mondúver, dominando la plana costera. Su planta irregular de origen musulmán fue ampliada y nuevamente fortificada con torres circulares de mampostería y arcos adovelados de medio punto en el acceso. El castillo de Santa Ana se encuentra situado sobre un cerro que domina la población de Oliva. Su configuración responde a las obras realizadas en la segunda mitad del siglo XVI. Su planta es rectangular, reforzada por sendas torres circulares en dos ángulos diametralmente opuestos. En el torreón del Sureste se conserva una curiosa estancia cubierta con una bóveda anular que descansa sobre un pilar central. Sus fábricas están ataludadas formadas por mampuestos de gran tamaño y huecos enmarcados por potentes piezas de sillería.

En el valle de Cofrentes-Ayora han sido catalogados ocho castillos de los cuales cuatro han sufrido transformaciones para ser reconvertidos en fortificaciones palaciegas: El castillo de Cofrentes se ubica sobre un promontorio rocoso en la confluencia de los ríos Júcar y Cabriel. La estratégica situación de este castillo ha sido probablemente la causa de su uso continuado hasta las guerras carlistas. De origen musulmán, la antigua torre del homenaje se encontraba situada en la parte más alta del promontorio y en la actualidad se encuentra totalmente arrasada. Dispone de dos líneas de defensa. Ambas pertenecen a construcciones posteriores al castillo musulmán original. La exterior dispone de un arco de acceso flanqueado por dos torres circulares. El resto de torres de esta línea de defensa también son de planta circular. La segunda línea de defensa se corresponde con la residencia palaciega propiamente dicha. La entrada se realiza en codo para protección de posibles ataques, accediendo al patio de armas reconvertido en patio porticado como demuestran los restos de pilares de ladrillo que lo rodean. Este patio está pavimentado con guijarro de canto formando una figura radial. Este claustro se encuentra rodeado de dependencias entre las que se descubren los restos de una cocina y de una capilla en las pandas Oeste y Sur respectivamente. En las pandas Norte y Este se sitúan sendos cuerpos edificatorios donde, probablemente, se ubicaban las dependencias palaciegas a juzgar por los restos de yeserías decoradas que adornan las jambas de los huecos.

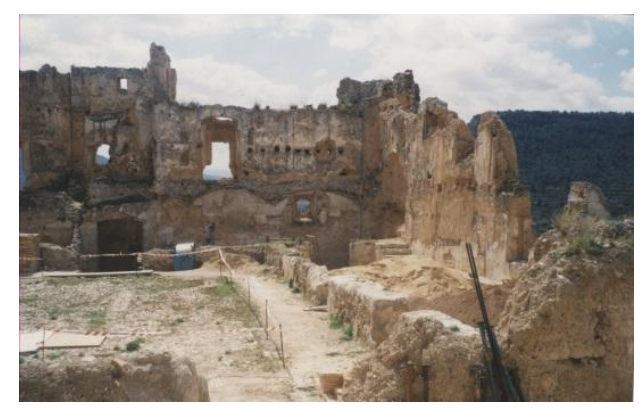

Fig. 3- Interior del castillo-palacio de Cofrentes con el patio de armas convertido en "cortile" pavimentado con guijarro de canto formando una figura radial

El Castillo de Chirel, en Cortes de Pallás, es una de las fortalezas que mayores vestigios conserva sin haber sido intervenida. Es de origen musulmán y fue reconstruida en el siglo XV. Aunque la planta mantiene la forma irregular de la fortaleza árabe, los grandes cuerpos edificatorios son rectángulos regulares con arcos de piedra, huecos recercados por sillares y algunas esquinas están reforzadas con sillares, siguiendo las características propias de las construcciones defensivas del XV.

El castillo de Jalance consta de dos partes bien diferenciadas, el recinto fortificado superior y la 
zona inferior o albacar de época islámica. Conserva la plaza de armas cristiana, protegida por muro perimetral poligonal y en los ángulos torres de planta circular. Se llega a esta zona por una escalinata de época moderna que da acceso a distintas dependencias. Siguiendo el valle hacia su desembocadura llegamos al Castillo de Ayora. Se encuentra sobre un cerro que domina la población. En la antigua celoquia se conservan los restos de una cocina palaciega con vertedero de basuras, pilas de ladrillo y mesa comunal junto al aljibe abovedado. En el extremo Sur se sitúa la plaza de armas, pavimentada con guijarro y escaleras de piedra, elementos que se corresponden con las reformas del siglo XV.

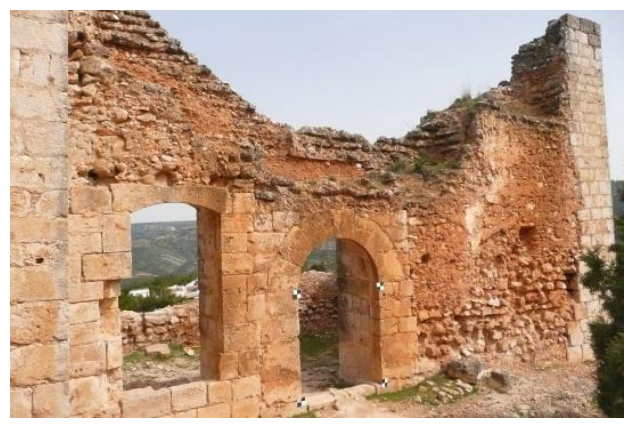

Fig. 4- Detalle de arcos y huecos recercados con sillería del siglo XV en el castillo de Chirel

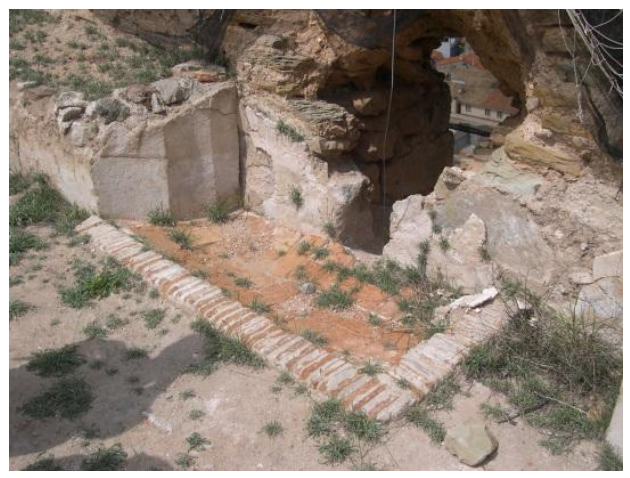

Fig. 5- Detalle de la pila de desagüe en las cocinas del Castillo de Ayora pertenecientes al siglo XV

Sólo cinco castillos fueron catalogados en la comarca del Camp del Turia, de los cuales sólo uno ha sido transformado en residencia palaciega, el Castillo-Palacio de los Boil en Bétera. Situado en zona urbana se encuentra desfigurado por las transformaciones que ha sufrido al pasar del carácter defensivo a palacio señorial. De su origen musulmán solo quedan vestigios en los tapiales de su estructura muraría. Actualmente ha sido intervenido y convertido en centro cultural.

La Canal de Navarrés cuenta con ocho castillos y sólo en uno de ellos se distinguen elementos que hacen pensar que tuvo un uso residencial palaciego: el Castillo de Bolbaite. Se trata de adornos en yesería de época tardogótica flamígera. Existe un torreón de época cristiana en sillería con una escalera gótica de acceso.

En la Hoya de Buñol existían cinco castillos y el único que mantuvo el uso y fue residencia palaciega es el Castillo de Buñol, situado en la parte alta de la población. Su lienzo principal situado al Noreste alberga tres torres almenadas. Se accede a través de la torre central mediante un puente. De la época musulmana es la torre albarrana que protege el acceso sur y conduce al recinto que ocupan la casa del Gobernador y la iglesia. Este último recinto fue convertido en el cuerpo edificatorio residencial.

Sólo tres castillos han sido catalogados en la comarca de la Plana Utiel-Requena y dos de ellos mantuvieron el uso a través de las diversas reformas que los convirtieron en edificios residenciales nobiliarios: El Castillo de Chera y el de Requena. El primero, como la mayoría de los castillos de la provincia de Valencia es de origen musulmán. El estado ruinoso en que se encuentra no permite adivinar vestigios que daten su etapa palaciega, sin embargo la planta y organización espacial del mismo delatan las transformaciones cristianas de época renacentista: Planta cuadrangular con altos muros, con bastiones esquineros, todos ellos ataludados y de sección cuadrada. Aunque mantiene los muros de tapial de la época musulmana, también se distinguen tramos de sillarejo careado que muestran los puntos donde fue intervenido para su conversión residencial. Se denomina Castillo de Requena a la parte Norte del recinto amurallado de La Vila que constituía la primera alcazaba anterior al siglo XI. Sin embargo, su elemento principal, es decir, la torre mayor es del siglo XV construida con 
sillería y un acceso en esviaje con arco adovelado de medio punto correspondiéndose con la forma de construir del gótico tardío. Se aprecia también el patio de Armas.

Dos castillos protegían la comarca de la Ribera Baja: el Castillo de Corbera y el de Cullera pero sólo este último fue ampliado para adaptarlo a nuevas necesidades. Es de origen andalusí del siglo XI y en el XII se le añade el amplio recinto amurallado del albacar. Su posición estratégica sobre un cerro que domina una amplia zona de la desembocadura del río Júcar lo convierten en un bastión inestimable y, por lo tanto, no fue abandonado como la mayoría de los castillos musulmanes. Perteneció a la Orden de San Juan del Hospital que lo ampliaron, reforzaron y convirtieron en Encomienda.

En L'Horta Nort sólo existe el Castillo de Cebolla que ya fue abandonado en época medieval.

La comarca de la Costera dispone de cuatro castillos de los cuales el Castillo de Montesa y el de Xátiva fueron adaptando sus estructuras a nuevos usos, probablemente debido a la magnífica posición estratégica que tienen. El castillo de Montesa se halla sobre un promontorio formando un conjunto inexpugnable. Aunque su origen es musulmán la configuración que tiene en la actualidad responde a las obras de readaptación realizadas en el siglo XVI por la Orden de Montesa hasta que en 1748 un terremoto arruinó el conjunto. El castillo de Xátiva es de origen prerromano. Se divide en dos áreas denominadas Castillo Mayor y Castillo Menor con un acceso común. Aunque conserva construcciones islámicas como es la torre del Sol, también pueden contemplarse construcciones cristianas posteriores como es la capilla gótica de Santa María situada en un conjunto que tuvo treinta torres y una docena de aljibes. Ello da una idea de la monumentalidad de este castillo. De esta época tardogótica se han conservado algunas bóvedas ojivales, muros y huecos recercados de cantería.

\section{Conclusiones}

Los castillos que mantuvieron su importancia tras la reconquista fueron fortificados, y adaptados a nuevas necesidades sociales, tanto defensivas como de residencia palaciega. Tras analizar cuáles son estos castillos y su localización se puede concluir que se trata de fortalezas situadas en puntos muy estratégicos, sobre cerros o peñas que dominan una vía de comunicación fluvial o terrestre. Es el caso de los castillos del valle del Palancia donde, además de controlar el río, también controlan la vía de comunicación entre Valencia y Aragón, ya que, paralelamente al río circulaba el antiguo camino mayor que unía Teruel con Valencia: Torres Torres, Beselga, Puinera y Sagunto.

También es el caso de los castillos del valle de Cofrentes-Ayora ya que se encuentran en la vía de comunicación entre el Reino de Valencia y Castilla: Cofrentes, Chirel, Jalance y Ayora.

Sin embargo, existen otros castillos que fueron conservados en época cristiana y no se encuentran en una vía de comunicación importante. Son aquellos que se ubican en núcleos de población que crecieron notablemente y, por lo tanto, el señor del castillo lo conservó y convirtió en su residencia palaciega. Es el caso de Castielfabib, Cofrentes, Bétera o Xátiva. Alguno de estos núcleos mantuvieron su crecimiento a lo largo del tiempo y otros, como Castielfabib, perdieron importancia y la población aprovechó la sólida edificación del castillo para destinarlo a almacén o fragua.

Aquellos castillos que dominaban un señorío cuyos núcleos de población fueron decreciendo con el paso del tiempo o se encontraban controlando territorios que dejaron de ser puntos estratégicos fueron abandonados $\mathrm{y}$ sus estructuras se encuentran totalmente arruinadas y cubiertas por la vegetación.

\section{Notas}

(1) Los profesores que participaron en este proyecto de investigación fueron: Concepción López González, Jorge García Valldecabres y Simeón Couto López del Departamento de Expresión Gráfica Arquitectónica; Francisco Taberner Pastor del Departamento de Urbanismo; y $\mathrm{M}^{\mathrm{a}}$ Luisa Navarro García adscrita al Departamento de Construcciones 
Arquitectónicas. Todos ellos pertenecientes al Instituto Universitario de Restauración del Patrimonio.

(2) Los resultados de esta investigación pueden consultarse en el libro "Catálogo Razonado de Castillos de la Provincia de Valencia". Valencia, 2014.

(3) El conocimiento de la evolución constructiva de la iglesia-fortaleza de Castielfabib fueposible gracias a los análisis metrológicos y geométricos que se realizaron sobre un levantamiento de planos riguroso de este conjunto arquitectónico. Para mayor información de los resultados obtenidos en esta investigación se puede consultar el artículo titulado "Los orígenes de la iglesia-fortaleza de Castielfabib. Análisis gráficos”. Concepción López González y Jorge García Valldecabres. Revista EGA n ${ }^{\circ}$ 20. Pag. 112-123. Valencia, 2012.

\section{Referencias}

Ariño A. (1990). "Estudio histórico, estilístico y comparativo de los castillos y restos de arquitectura militar de defensa" en Valencia y su entorno. Tesis doctoral.

López C., García J., Couto S., Taberner F., Navarro Mª L. (2014). Catálogo razonado de castillos de la provincia de Valencia. Ed. Obrapropia S.L. Valencia.

López C., García J. (2012). Los orígenes de la iglesia fortaleza de Castielfabib. Análisis gráficos. Revista EGA n ${ }^{\circ}$ 20. Valencia. pp. 112-123.

López P. (2002). Los castillos valencianos en la Edad Media. Materiales y técnicas constructivas. Generalitat Valenciana Ed. Valencia. 
